\title{
Research on the Role of Financial Industry in Eliminating Overcapacity in Hebei Province
}

\author{
Hailong Liu ${ }^{1 . a}$ \\ ${ }^{1}$ Appraisal Center for Environment and Engineering Ministry of Ecology and Environmental
}

\begin{abstract}
In order to solve the problem of excess capacity, Hebei Province has taken various measures to strictly implement the Guiding Opinions on Resolving Serious Overcapacity Contradictions issued by the State Council. In this process, most of the measures taken are administrative intervention, and the relationship among management measures, market rules and economic factors is not very clear. Based on this, this paper, starting from the excess capacity of Hebei iron and steel industry, analyses the relationship between investment return rate and investment ratio, and the relationship between profit and reduced capacity of iron and steel industry. On the basis of the analysis and the background of deepening the structural reform of supply side, this paper puts forward effective measures to solve the excess capacity of iron and steel industry.
\end{abstract}

\section{INTRODUCTION}

In recent years, the steel industry has become increasingly depressed and the profit level has become worse and worse. Although a number of measures have been taken, the results are not obvious. Therefore, in order to solve this problem, the state puts forward the structural reform of supply side on the basis of eliminating excess capacity.

The purpose of this paper is to study the causes of excess capacity in iron and steel enterprises, analyze the impact of financial market on iron and steel production capacity through investment, business income and other aspects, and put forward a more reasonable investment mix and the goal of reducing production capacity, so as to minimize excess capacity and accelerate the structural reform of supply side.

The research on finance and industrial development began in the 18th and 19th centuries abroad. Foreign scholars such as Ricardo and Schumpeter have found that financial support can promote the healthy and sustainable development of industry. They systematically studied the role of financial support, and put forward that if the government wants to adjust the industrial structure and achieve economic growth, it can not do without financial support. Badget analyzed the role of Finance in promoting industrial development, pointed out that a better financial system can provide financing services for industrial projects, and then promote industrial restructuring [1].

Beck and Levine believe that whether industrial restructuring can be successful or not, the most important thing is to let the financial system play a role in promoting technological innovation, so as to optimize the industrial structure [2]. Thomas Hellmann and Marco $\mathrm{Da}$ Rin argue that financial institutions are the most important intermediaries in financial markets and play an irreplaceable role in the healthy development of industry [3].

Since the end of 1990s, the research on the relationship between economy and finance has been more in-depth, and there have been many achievements. Among them, Liu Shijin studied the problem of financial and industrial development earlier. He proposed that financial support is an important breakthrough to promote industrial development. Whether financial innovation and reform can succeed depends on whether it can provide support for industrial upgrading and development, and the level of support can be used as the main criterion for measuring the success of innovation and reform [4].

\section{THE IMPORTANCE OF RESOLVING OVERCAPACITY}

Although the structural reform of supply side has provided policy support, there are still some very difficult problems to solve in the process of resolving excess capacity. SISCO has predicted that the reduction of 100 million tons of steel production capacity may mean that hundreds of thousands of iron and steel workers will face job readjustment. Hebei Province has always been a province with large iron and steel output, so the task of reducing production capacity is also very heavy, facing a large number of iron and steel workers placement and employment problems. It is worth noting that private iron and steel enterprises account for the majority. From the point of view of enterprise operation,

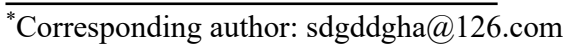


the asset-liability ratio of some iron and steel enterprises is as high as $80 \%$, which proves that the profit level of private iron and steel enterprises is very limited [5]. In recent years, due to the main reasons of imperfect financial market mechanism, imbalance between supply and demand, and low degree of industrial agglomeration, excess capacity has been created. In the process of resolving excess capacity, this part of loss-making enterprises will bear the brunt, which is also a difficult problem faced by Hebei Province in resolving iron and steel production capacity. Therefore, it is very important and necessary to study the role of financial support in the transformation and upgrading of Hebei iron and steel industry.

\section{FINACIAL OPERATION IN HEBEI PROVINCE}

From 2006 to 2015, the RMB deposit balance of banking financial institutions in Hebei Province increased year by year. The RMB deposit balance increased from 1.26 trillion yuan to 4.86 trillion yuan, with an average annual growth of 0.36 trillion yuan, an increase of about $28.6 \%$, showing a linear growth relationship. Renminbi loan balance increased from 0.74 trillion yuan to 3.2 trillion yuan, an average annual growth of 0.25 trillion yuan, an increase of about $33.8 \%$. The growth trend of RMB loan balance is consistent with that of RMB deposit, but the growth rate is faster than that of deposit balance.

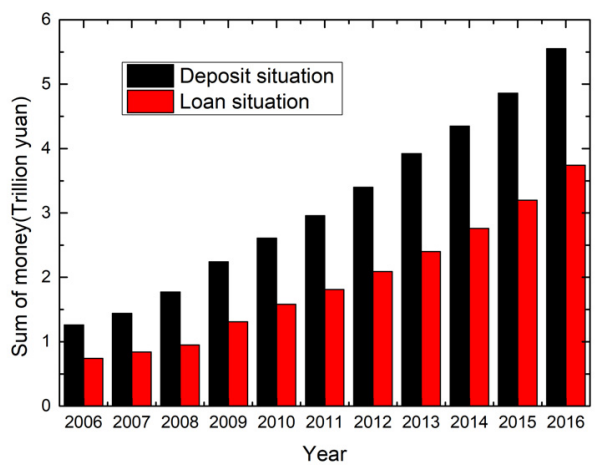

Figure 1 Changes in Renminbi Deposits and Loans

From 2006 to 2015, the warning line that the proportion of people's money deposited and lent is less than $80 \%$ has worked well, as shown in Fig. 2. Under the severe influence of the international financial crisis, the downward pressure of China's economy is increasing, the level of development of the iron and steel industry in Hebei Province has fallen rapidly, the volume of iron and steel exports has shown negative growth, a large number of migrant workers have begun to return home to start businesses, and the steel industry may face the risk of a hard landing. In 2008, the proportion of deposits and loans dropped to $53.67 \%$, and the economic development was slow.

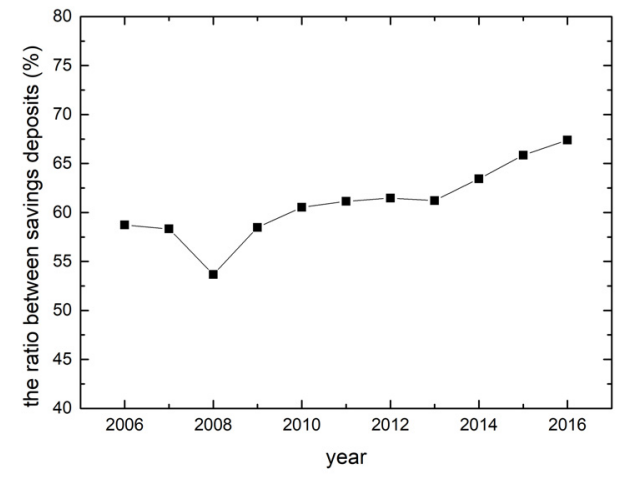

Fig. 2 Change of RMB Deposit-Loan Ratio

In order to get rid of this predicament quickly, the Chinese government formulated ten measures in November 2008 to expand domestic demand and promote rapid economic growth [6]. In order to land these ten measures, preliminary estimates indicate that in two years, it will cost about 4 trillion yuan. In response to the call of the state, the government of Hebei Province has continuously enriched and improved various policies and measures and formulated a package plan to deal with the adverse impact of the international financial crisis on the economy of Hebei Province. After one year's efforts, the proportion of RMB deposits and loans has increased to $58.48 \%$. The economic development in 2014 and 2015 has entered a period of medium and high speed, and the proportion of deposits and loans has increased considerably, which needs to be paid attention to.

\section{FINANCING SITUATION OF IRON AND STEEL ENTERPRISES}

Iron and steel industry is a capital-intensive industry, so how much capital investment can determine the development speed and innovation level of enterprises. Generally speaking, according to the development mode of iron and steel enterprises, the investment is divided into three categories: investment in new projects, investment in expansion projects and investment in reconstruction projects. During 2006-2010, the investment quota for new projects in the iron and steel industry was maintained at about 20-25 billion yuan, and the investment quota for reconstruction and expansion projects was maintained at about 5-15 billion yuan. Under the policy of eliminating backward capacity and eliminating excess capacity, the investment quota of new construction projects has dropped sharply after 2010, while the investment quota of construction and expansion projects has risen sharply. See Figure 3 for details. 


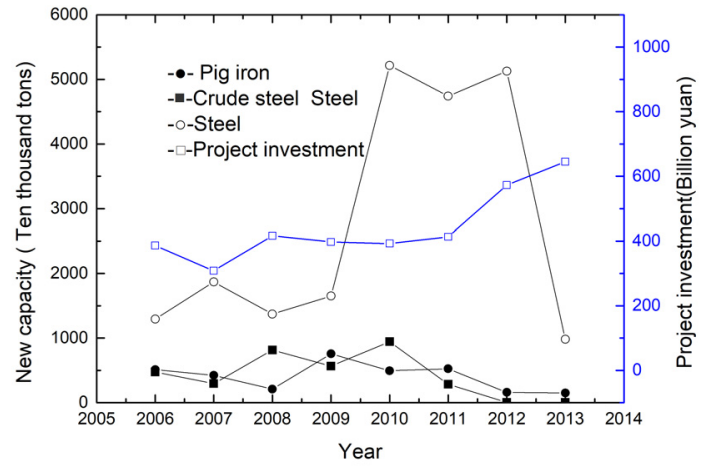

Figure 3 Changes in Project Investment of Iron and Steel Enterprises in Hebei Province

\subsection{Output of Iron and Steel Enterprises}

Hebei Province began to solve the excess capacity of iron and steel in 2003 and restrict new capacity. In 20062015 , because the scale of state-owned enterprises is obviously larger than that of non-state-owned enterprises, the state-owned enterprises account for about $42 \%$ of the total production of $68 \%$ of the total crude steel. In terms of labor efficiency, state-owned enterprises account for $80 \%$ of the workers in the industry. Only $68 \%$ of crude steel has been produced in the industry. From the data, it can be seen that the labor efficiency of state-owned enterprises is obviously lower than that of non-stateowned enterprises.

From 2006 to 2012, there was a logarithmic growth trend, and the growth rate decreased significantly in 2012. The crude steel output was controlled below 2000 tons in 2013-2015, while the pig iron output was controlled below 180 million tons. The growth of the two is similar. From the figure 8 , it can be clearly seen that the peak production capacity of crude steel in Hebei Province is about 180 million tons.

From 2006 to 2015, the new steel production capacity of construction projects increased linearly, with an annual growth rate of about 185 billion tons. The details are shown in Figure 4.

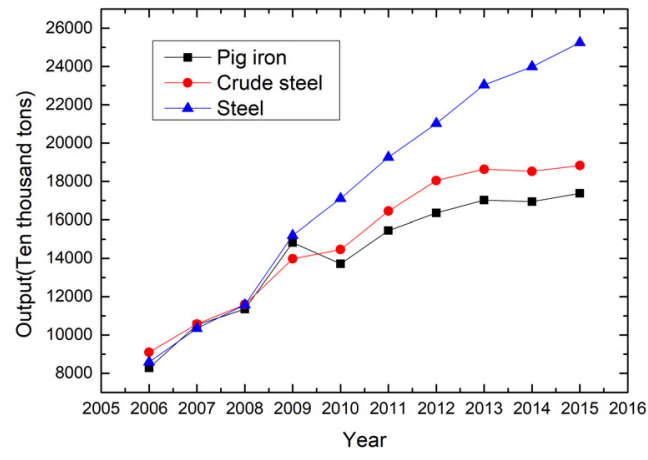

Figure 4 Changes in Iron and Steel Production in Hebei Province

\subsection{Profit Situation of Iron and Steel Enterprises}

Because of the slow technological renewal, the labor efficiency of Hebei iron and steel enterprises is difficult to improve. The average steel production per person is 500 tons, but the labor cost is increasing. According to the data of recent years, the average labor cost has been maintained at about 90,000 yuan, the increase of labor cost exceeds the increase of labor productivity, and the reason of overcapacity has resulted in the decline of product price. Under the pressure of the decline of product price, the proportion of labor cost in the added value of iron and steel industry has decreased. Profits also fell. Therefore, the profit and tax of iron and steel industry show a double downward trend, and the law of change is quite consistent, as shown in Figure 5.

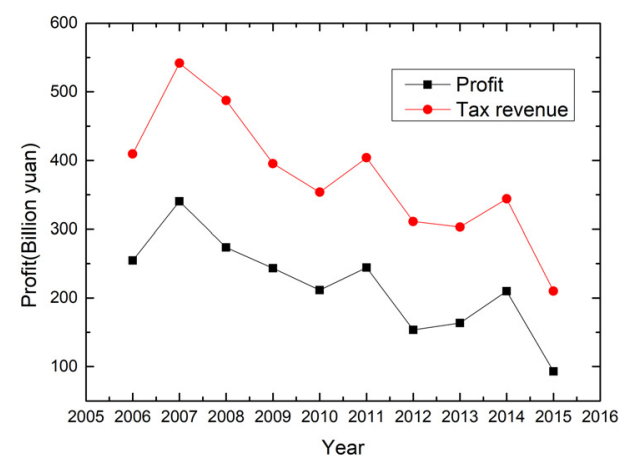

Figure 5 Profit and Taxation of Iron and Steel in Hebei Province

Sales revenue of iron and steel increased year by year, basically maintaining an annual increase of 200 billion yuan, and remained stable after 2011, even a phenomenon of sales revenue decline. Although the sales revenue of iron and steel industry is considerable, and the sales revenue accounts for a large proportion of industrial added value, the sales profit is declining year by year, as shown in Figure 6. At the same time, the new capacity of iron and steel is not optimistic, falling to the lowest level in many years in 2013, as shown in Figure 7.

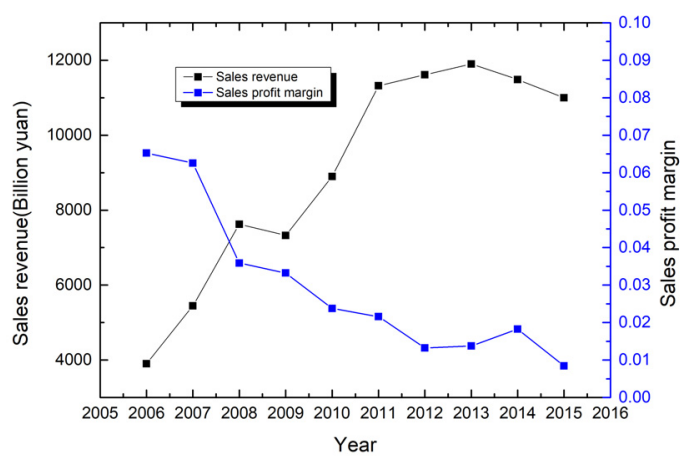

Figure 6 Changes in sales revenue and profit margin of iron and steel in Hebei Province 


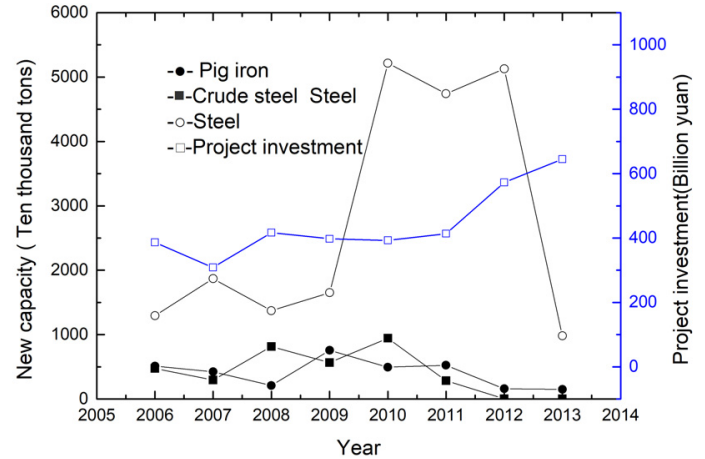

Figure 7 Changes in New Iron and Steel Production Capacity and Project Investment in Hebei Province

Project investment is increasing year by year, while profits and taxes are declining year by year. It can be seen that overcapacity of iron and steel has reached an impatient level.

\section{THE IMPACT OF FINANCE ON DISSOLVING CAPACITY}

\subsection{Rational Proportion of Construction Project Investment}

Over the past 10 years, as the steel industry has maintained a growth trend, financial institutions regard it as a "high-quality customer", thus investing a large amount of credit funds. For the early stage of audit, financial institutions tend to take the form of lack of uniform and standardized audit standards.

For iron and steel enterprises with excess capacity, it is difficult for commercial banks to substantially reduce the scale of credit. Once financial institutions decide to take all-round measures, the capital chain of these enterprises is likely to break down and bankruptcy may occur. If not well controlled, because of the substantial increase in non-performing loans of banks, it may eventually lead to the outbreak of credit risk of financial institutions. According to preliminary statistics, every $20 \%$ reduction in excess capacity may bring nonperforming loans to financial institutions, about 1 trillion yuan, accounting for about $1 \%$ of the bank's RMB loan balance. Sometimes financial institutions have to continue to provide more credit support for iron and steel enterprises with excess capacity in order to mitigate the risk of increasing non-performing loans, thus falling into a vicious circle. But most of these loans are used for scale expansion, but seldom for product innovation and transformation [7].

The transformation of product innovation requires the investment of special funds, so it is necessary to upgrade some of the original enterprises. Reconstruction projects refer to projects that have already formed a scale and have a certain production capacity, but because the original process equipment and production technology are not advanced enough, resulting in high production costs, high capacity consumption, or small-scale resulting in diseconomies of scale. In order to improve the production efficiency, funds are invested in the renovation and upgrading of the original equipment and plant. Therefore, the proportion of investment in reconstruction projects in the total investment of new construction, expansion and reconstruction can directly reflect the ability of iron and steel industry to self-renew and defuse excess capacity.

The ratio of profit to total investment in iron and steel industry, i.e. the return rate, can directly reflect the value of investment in iron and steel projects. According to the data from 2007 to 2013, it can be concluded that the return rate of investment in iron and steel projects is basically on a downward trend. The return rate of investment declines greatly between 2008 and 2012, and rises in 2011. Trends. As shown in Figure 8.

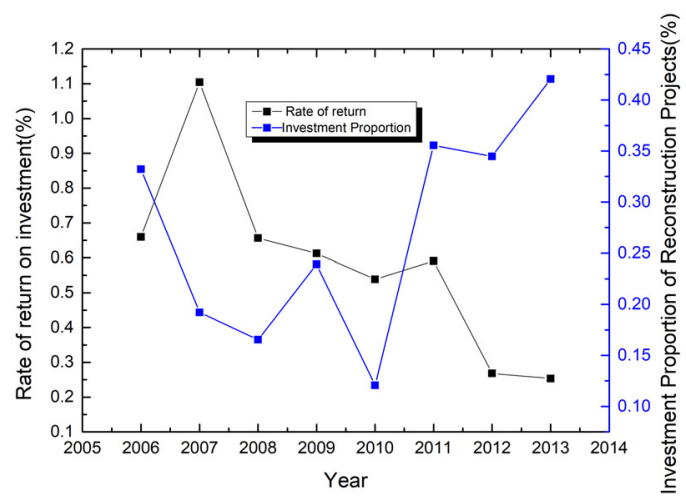

Fig. 8 The relationship between the investment return rate of iron and steel industry and the investment ratio of reconstruction projects

As can be seen from the above chart, only when the investment proportion of the reconstruction project has a significant turning point and remains above $30 \%$, can the return rate of the project investment increase.

\subsection{Reasonable Target of Dissolving Production Capacity}

The most important thing is that we can't build new backward production capacity, especially expand production capacity under the pretext of technological transformation and transformation and upgrading. According to the relationship between supply and demand in the market, we can set the peak value of total iron and steel production in Hebei Province. For the existing excess capacity, enterprises whose environmental protection, safety in production and energy consumption can not meet the statutory standards should be shut down and withdrawn in an orderly manner according to relevant laws and regulations. Iron and steel enterprises should correctly handle the relationship between quantity and quality in the process of dissolving excess capacity, improve the quality of products and accelerate product upgrading.

Profits of the steel industry have been declining for many years. In 2011 and 2014 alone, there has been a slight increase. In these two years, the compression capacity of the steel industry has been more than 20 
million tons, as shown in Figure 9. It can be seen that a substantial reduction in capacity is the greatest driving force to reverse the downward trend of profits.

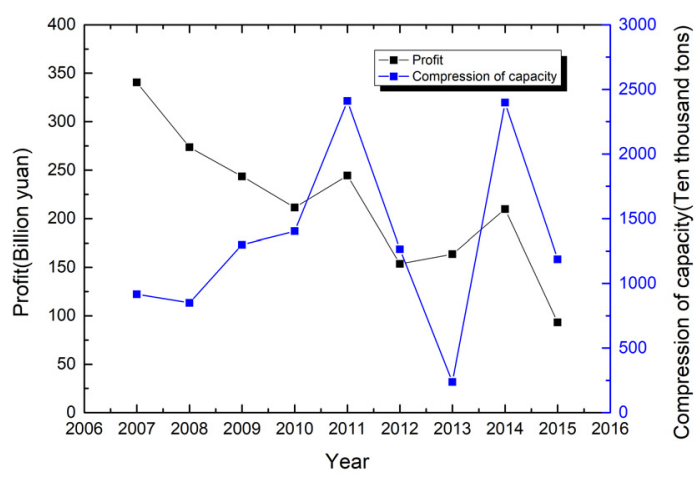

Figure 9 The relationship between profit and reduced capacity in iron and steel industry

\section{CONCLUSION}

This paper introduces the current situation of iron and steel industry from the perspective of finance, productivity and structural reform, combs the structural problems of iron and steel industry, and combines with the structural reform of supply side, analyses the causes of excess capacity in China's iron and steel industry. Whether from the macroeconomic slowdown, the decline in the overall profitability of the industry at the meso level or from the micro perspective, the allocation of enterprise labor force is restricting the healthy development of the iron and steel industry. After data analysis, the following conclusions are drawn:

First, relying on the government's administrative means to give credit support to the steel industry and increase investment efforts have little effect on the profitability of the steel industry.

Second, the peak value of iron production in Hebei's iron and steel industry is about 180 million tons.
Thirdly, the investment of reconstruction project should account for more than $1 / 3$ of the total investment of the project, so as to increase the investment yield of iron and steel project.

Fourthly, only by keeping the compressed capacity above 20 million tons can we reverse the declining trend of steel profits.

Under the structural reform of supply side, only by making rational use of the correct guiding role of Finance and intensifying efforts to eliminate excess capacity, can the iron and steel industry of Hebei Province return to the track of normal development.

\section{References}

1. Bagehot, W. Lombard Street: A Description of the Money Market. Philadelphia: Orioned, 1991.

2. Beck, T, R, Levine, Norman $\cdot \mathrm{L}$. Finance and the Source of Growth[J]. Journal of Financial Economics. 2000, (1):261-300.

3. Marco Da Rin, Thomas Hellmann. Banks as Catalysts for Industrialization[J]. Journal of Financial Intermediation, 2002, (11): 366-397.

4. Liu Shijin. Creating a favorable financial environment for industrial upgrading and development [J]. Shanghai Finance, 1996, (4).

5. Ni Runsen. Research on Debt Problem of China's Iron and Steel Industry from the Perspective of Supply-side Institutional Reform [D]: [Master's thesis]. Shanghai: Shanghai Academy of Sciences, 2017.

6. Jinshengxue. China's financial dilemma and Countermeasures in overcapacity [J]. Modern Economic Information, 2016, (13): 280-281.

7. Zheng Liangfang. Financial industry should play a leverage role in solving overcapacity $[\mathrm{J}]$. Finance and Economy, 2013, (11): 4-6. 